\title{
Determination of the residual stress distribution of steel bridge components by modelling the welding process
}

\author{
Evy Van Puymbroeck*,a, Wim Nagy ${ }^{\mathrm{a}}$, Ken Schotte ${ }^{\mathrm{a}}$, Zain Ul-Abdin ${ }^{\mathrm{a}}$, Hans De Backer \\ ${ }^{\mathrm{a}}$ Ghent University, Department of Civil Engineering, Belgium \\ Evy.VanPuymbroeck@UGent.be,Wim.Nagy@UGent.be, Ken.Schotte@UGent.be, Zain.UlAbdin@UGent.be, \\ Hans.DeBacker@UGent.be
}

\begin{abstract}
Welding operations are typically used for the connections in steel bridges. Several locations with residual stress concentrations exist within the welded parts due to the welding itself, but also because of the influence of geometric discontinuities on the flow of the stresses. This can result in fatigue failure. The knowledge of residual stresses is essential to determine the effect of the residual stresses on the fatigue life behaviour of the welded components [1].

In this paper, the residual stresses of two flat plates of construction steel S235 welded together are determined by modelling the welding process. The temperatures during the welding operations are calculated in a thermal analysis, taking into account the thermal properties and behaviour of the steel. The heat input during welding is implemented on the model by defining a thermal flux for the different time steps representing the passage of the welding torch. A double ellipsoidal volume heat source is used to describe the heat flow through the material for a moving heat source. The distribution of the thermal flux is considered, taking into account the thermal material properties of steel as a function of temperature. After the calculation of the temperatures introduced during the welding process in the thermal analysis, a subsequent mechanical analysis is performed. The temperatures are introduced as a time dependent load onto the model. The elements of the model in the fusion zone of the welding are activated based on their reached temperature. The finite element modelling predicts the residual stresses induced by the welding procedure which can later be verified through comparison with measured residual stress distributions.
\end{abstract}

Keywords: residual stresses, welding simulation, finite element modelling

\section{INTRODUCTION}

The construction of steel bridges requires welding of its steel components. Significant residual stresses exist within the welded parts due to differential thermal expansion of material under a nonuniform thermal field. After the passage of the welding torch, the steel cools down and material close to the heat source is constrained by material further away. This causes high tensile residual stresses around the welding region. Since tensile residual stresses tend to open cracks, they have a detrimental influence on the fatigue crack propagating under cyclic traffic loadings on the bridge [2]. Therefore, knowledge of the distribution of residual stresses in welded bridge components is essential to accurately estimate the crack development under fatigue loads.

Finite element modelling is often used to predict residual stresses in welded engineering structures. A sequentially coupled thermo-mechanical analysis is necessary to simulate the welding procedure and the occurring temperatures in the material and to calculate the effect of these temperatures on the residual stress state. The finite element modelling can predict the residual stresses as a consequence of a welding procedure which can be verified in a later stage through comparison with residual stress measurements on real-life bridge components. 


\section{FINITE ELEMENT MODEL}

\subsection{Geometry of the model}

Two S235 mild steel plates of size 500x200x4 mm are welded together in a continuous single pass using pulsed Gas Metal Arc Welding (GMAW). The welding parameters were designed to achieve full penetration of the weld pool through the plate thickness [3]. The welding parameters are given in Table 1.

Table 1. Welding parameters

\begin{tabular}{ll}
\hline Filler wire diameter D & $1 \mathrm{~mm}$ \\
\hline Contact tip to work distance $\mathrm{L}$ & $13 \mathrm{~mm}$ \\
\hline Torch angle & $90^{\circ}$ \\
\hline Welding speed S & $10.8 \mathrm{~mm} / \mathrm{s}$ \\
\hline Welding current I & $270 \mathrm{~A}$ \\
\hline Welding voltage $\mathrm{V}$ & $27.8 \mathrm{~V}$ \\
\hline
\end{tabular}

A three-dimensional transient model is built in Siemens NX11. The thermal analysis is sequentially coupled with the mechanical analysis. Linear brick-type elements were used for the model using the same mesh for the thermal and mechanical analysis comprising 391545 elements. However, for the mechanical analysis, a smaller number of nodes was taken into account to decrease the calculation time. The mesh near the deposition of the weld bead has a very fine mesh while the mesh is coarser as the distance to the weld seam increases. The model is shown in Fig. 1.

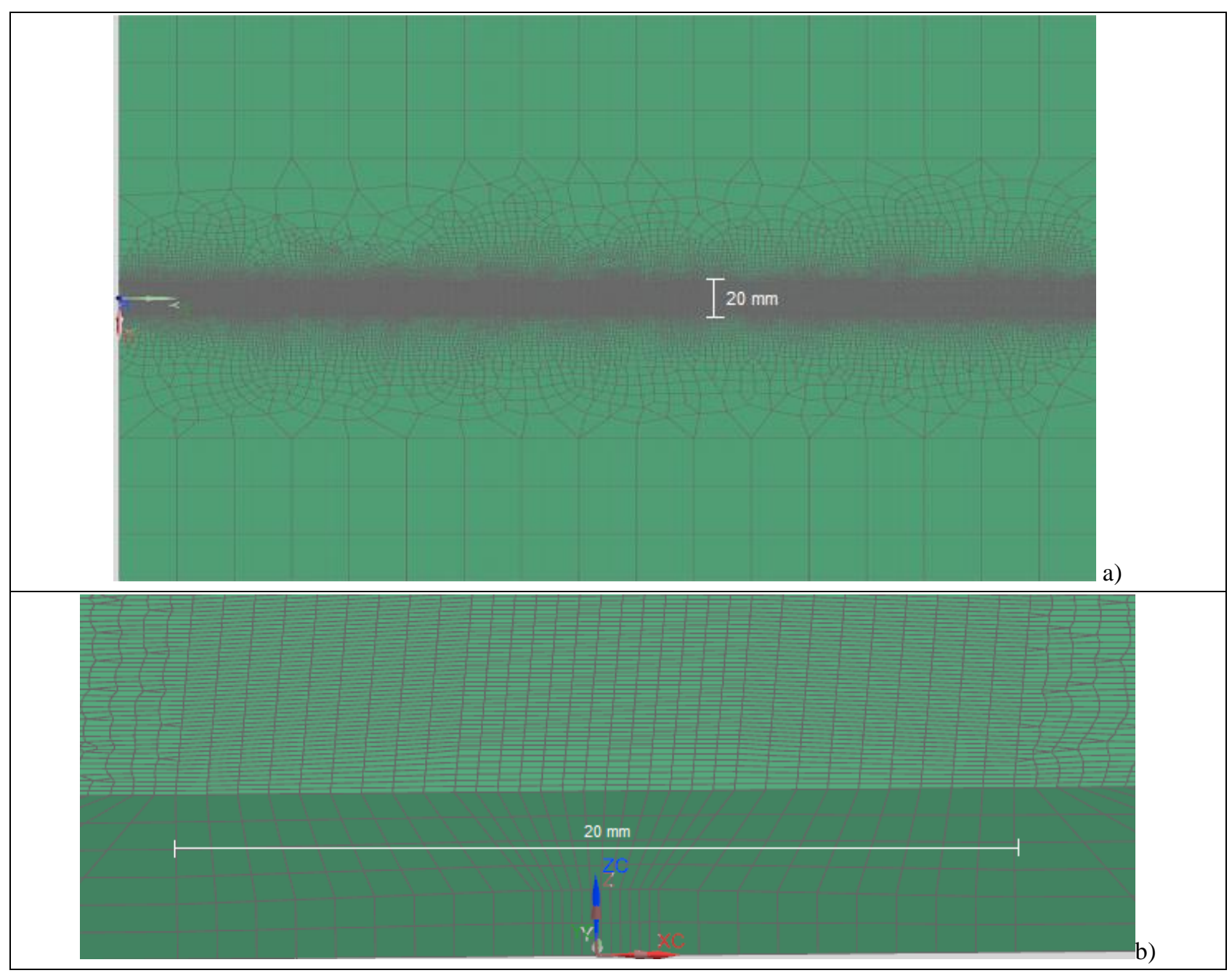

Fig. 1. a) Mesh used in analysis; b) Fine mesh near the weld seam 


\subsection{Boundary conditions}

In the thermal analysis, constant free convection with a convection coefficient of $15 \mathrm{~W} /\left(\mathrm{m}^{2} \mathrm{~K}\right)$ and simple radiation to the environment is applied to the external surfaces. An initial temperature of $18^{\circ} \mathrm{C}$ is assumed. For the mechanical analysis, the bottom side of the two plates is simply supported and the front faces of the two plates are fixed. To simulate the deposition of the weld bead resulting from the welding procedure, born dead elements are used which are activated when they reach a temperature of $1500^{\circ} \mathrm{C}$. This is the temperature for steel grade $\mathrm{S} 235$ where the material is located in the fusion zone [4].

\subsection{Loads}

For the thermal analysis, the heat input from the welding arc is used to determine the heat flux on the elements subjected to the heat of the welding. To assign a heat flux to these elements, the heat input is integrated over the penetration depth of the weld and over half of the weld bead width, taking into account the dimensions of the elements. The heat flux for each element is calculated for different time steps to simulate the passage of the welding torch with the considered welding speed. The last time step is the time where the temperature of the welded plates is cooled down again to environmental temperature. This results in a time dependent heat flux that is applied as a thermal loading in the thermal analysis. During the mechanical analysis, the calculated temperatures of the thermal analysis are introduced as a time dependent load onto the model.

\section{THERMAL ANALYSIS}

\subsection{Weld bead geometry}

The welding parameters are used to determine the weld bead geometry in order to define the thermal flux on the plates caused by the welding. Full penetration of the weld pool is achieved and therefore, the penetration of the weld $P$ is equal to the plate thickness of $4 \mathrm{~mm}$. The empirical equation by Chandel [5] for the GMAW process was used to predict the weld bead width W and is given in $E q$. (1).

$$
W=\frac{(D)^{0.567}(L)^{0.0106}(I)^{0.181}(V)^{0.86}}{(S)^{0.614}} \cdot \frac{1}{(10)^{0.218}}
$$

where $D \quad$ is the filler wire diameter,

$L \quad$ is the contact tip to work distance,

$I \quad$ is the welding current,

$V \quad$ is the welding voltage,

$\mathrm{S} \quad$ is the welding speed.

Considering the welding parameters given in Table 1, the weld bead width is equal to $6.9 \mathrm{~mm}$.

\subsection{Heat input}

A double ellipsoidal volume heat source proposed by Goldak et al. [6] is used to describe the heat flow through a material for a moving heat source. An ellipsoid described the zone before the welding arc while the zone after the welding arc is described by a second, less steep ellipsoid [6]. The heat source dimensions are based on the weld bead geometry while the total heat input is based on the welding parameters. A typical value of $77 \%$ is assumed for the arc thermal efficiency of the GMAW process [7]. This heat input is used to determine the heat flux which is applied as a thermal load during the thermal analysis.

\subsection{Thermal material properties}

Temperature dependent material properties for steel are used to model the influence of the welding process. The properties of the material are assigned in function of the high temperatures during welding. The thermal conductivity is increased above the melting temperature to simulate the convective heat transfer into the weld pool. Also the specific heat capacity, the emissivity, the thermal expansion coefficient [8] and the density in function of temperature are used to specify the 
material characteristics for the thermal analysis [9]. Isotropic hardening behaviour is included in the model. The temperature dependent material properties are shown in Fig. 2.

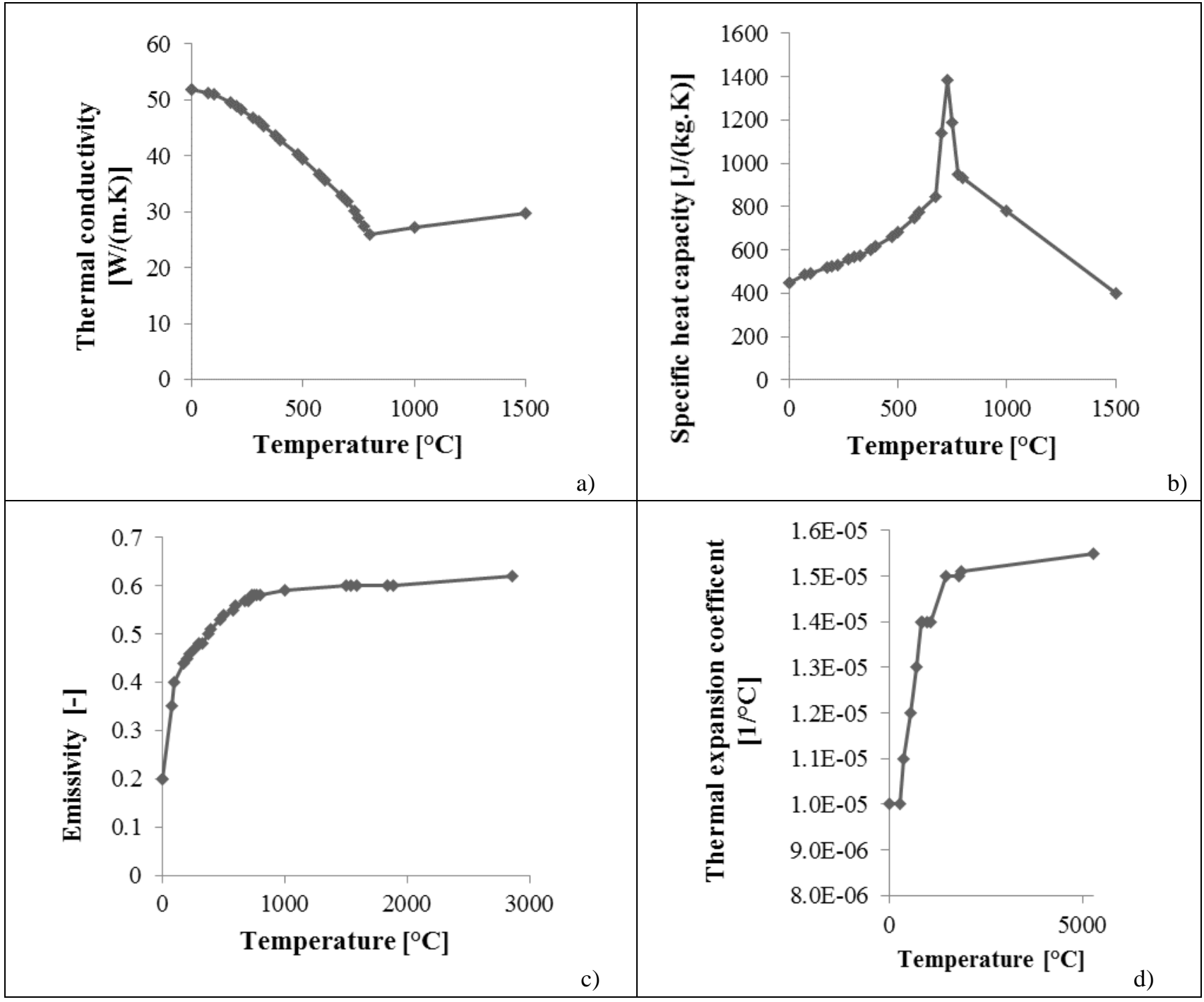

Fig. 2. Temperature dependent thermal material properties a) Thermal conductivity; b) Specific heat capacity; c) Emissivity; d) Thermal expansion coefficient

\subsection{Temperature results}

The thermal analysis simulates the heat introduced in the two plates and calculates the temperatures during the welding process. A contour plot of the temperature during welding is shown in Fig. 3 . The direction of welding is according to the $y$-axis indicated in the figure. 


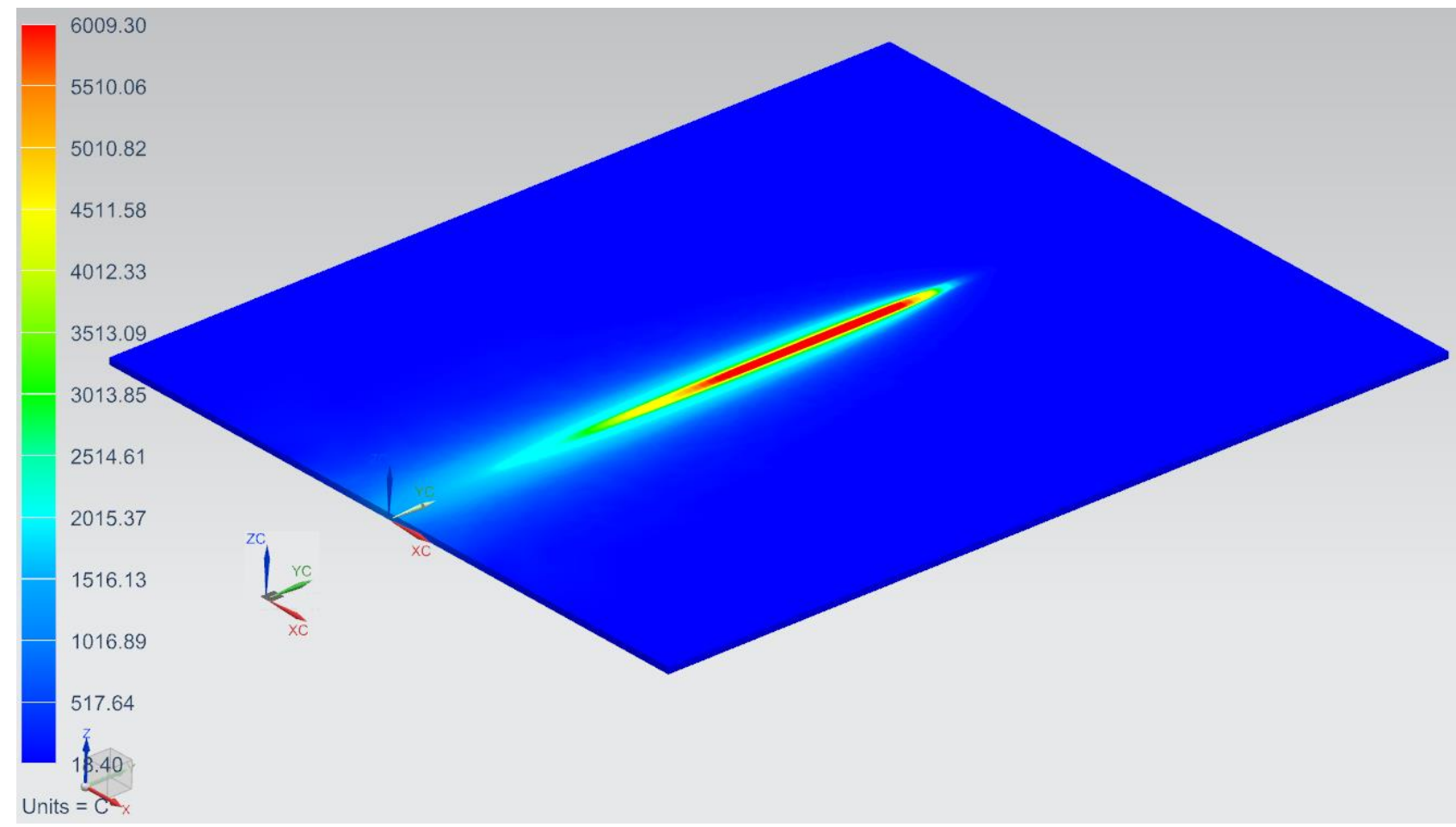

Fig. 3. Contour plot of temperature during welding (temperatures in ${ }^{\circ} \mathrm{C}$ )

\section{MECHANICAL ANALYSIS}

\subsection{Mechanical material properties}

The mechanical properties of the steel also have to be included in the model in function of the high temperatures introduced by the welding. The Young's modulus or modulus of elasticity has to be defined and it decreases with higher temperature [8]. The distribution is shown in Fig. 4.

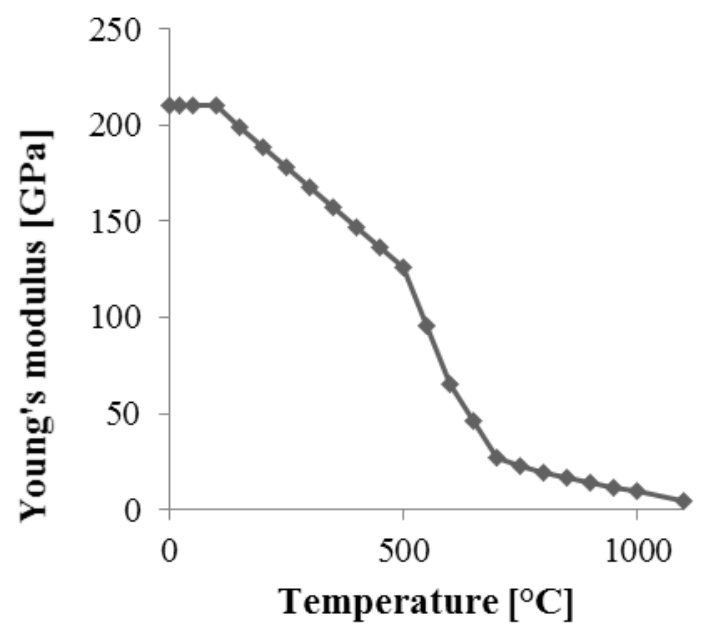

Fig. 4. Young's modulus

The stress-strain diagram for steel at elevated temperatures is specified in the model [10]. A plastic material behaviour with Von Mises yield criteria is assumed. The shear modulus is equal to 80GPa while the Poisson ratio is taken constant with a value of 0.3 in every direction of the material.

\subsection{Stress results}

The temperatures from the thermal analysis are implemented during the structural analysis as a time-dependent load while the model is simply supported at the bottom sides of the plates and the front faces are fixed. The deposition of the weld bead is simulated with born dead elements which 
are activated based on their reached temperature. The residual stress results are shown in Fig. 5. The stresses of the upper surface are displayed but the stresses in the upper and lower surfaces are almost identical. In a zone near the welding line, there are tensile residual stresses present with a maximum tensile residual stress of $270 \mathrm{MPa}$ in the weld bead. This maximum tensile residual stress is larger than the yield stress of the material of $235 \mathrm{MPa}$. Further away, there are compressive residual stresses present with a maximum of $150 \mathrm{MPa}$ in compression. The mean compressive residual stress outside the tensile yield zone near the weld is $52 \mathrm{MPa}$.

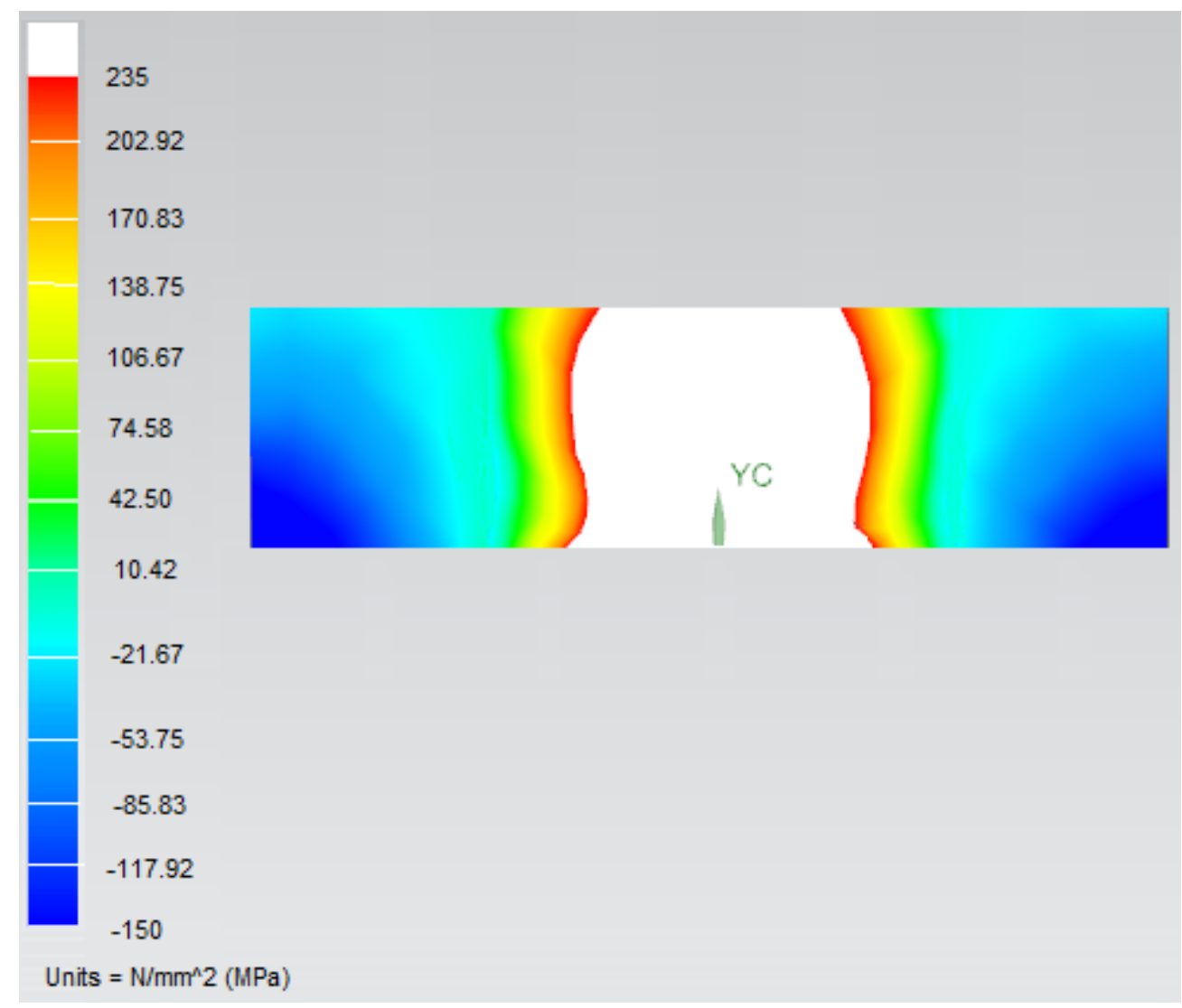

Fig. 5. Residual stress distribution

\section{COMPARISON WITH THEORETICAL RESIDUAL STRESS DISTRIBUTION}

The stress results of the welding of the two plates with the finite element modelling is compared with the effect of welds on a flat plate according to the 'Manual on the Stability of Steel Structures' [11]. The residual stress distribution in a centre welded plate is shown in Fig. 6. There are tensile residual stresses present in a zone of width $c$ near the weld and compressive residual stresses in the remaining parts of the plates.

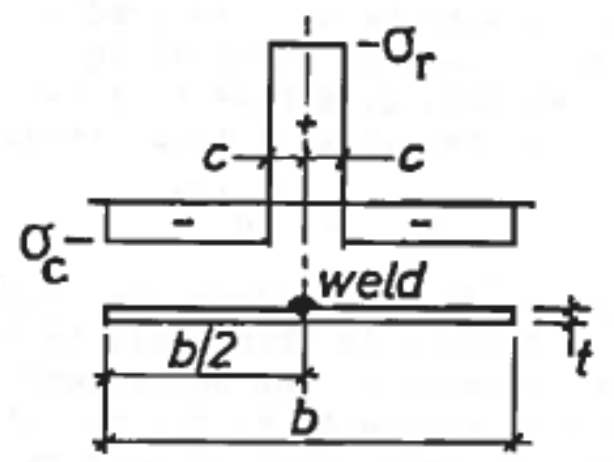

Fig. 6. Residual stress distribution centre welded plate [11] 
The value of $c$ for a continuous single pass weld is given by [11]:

$c=\frac{12000 \cdot p \cdot A_{w}}{\sigma_{r} \cdot \sum t}$

where $p \quad$ is the process efficiency factor equal to 0.77 for GMAW,

$A_{w} \quad$ is the cross-sectional area of added weld metal,

$\sum t$ is the sum of the plate thickness meeting at the weld,

$\sigma_{r} \quad$ is the plate yield stress.

When $c$ is calculated for the simulated welding procedure, a value of $40.4 \mathrm{~mm}$ is obtained. The uniform longitudinal residual stress $\sigma_{c}$ is given by [11]:

$\sigma_{c}=\sigma_{r} \cdot \frac{2 c}{(b-2 c)}$

For the simulated model, $\sigma_{c}$ is equal to $59.4 \mathrm{MPa}$. When the residual stress results from the finite element modelling are compared with the expected results based on this residual stress distribution, a relatively good agreement is found.

\section{SUMMARY}

A thermo-mechanical analysis of the welding procedure for a continuous single pass weld to connect two plates was performed with finite element modelling. The residual stress results are in good agreement with the expected residual stress distribution. In future research, similar finite element models can be used to determine the residual stresses of different welded bridge components and to calculate the fatigue life taking into account their residual stresses.

\section{REFERENCES}

[1] Zhao X.-L., Herion S., Packer J.A., Puthli S., Sedlacek G., Wardenier J., Weynand K., Van Wingerde A.M., Yeomans N.F. "Design Guide for Circular and Rectangular Hollow Section Welded Joints under Fatigue Loading". TÜV-Verlag, Köln, Germany, 2000

[2] Maddox S.J. "Fatigue strength of welded structures", Abington Publishing, Cambridge, UK, $2^{\text {nd }}$ edition, 1991

[3] Coules H.E., Cozzolino L.D., Colegrove P., Wen S.W. "Measurement and modelling of the transient thermal-mechanical strain field during GMA welding", Cranfield University, 2011

[4] Winczek J. "Modeling of heat affected zone in multipass GMAW surfacing S235 steel element", Proceedings of The 20th International Conference: Machine Modeling and Simulations MMS 2015, pp. 108-113, 2016

[5] Chandel R.S. "Mathematical modelling of gas metal arc weld features", Proceedings of the Fourth International Conference on Modeling of Casting and Welding Processes, pp. 109-120, 1988

[6] Goldak J., Chakravarti A., Bibby M. "A new finite element model for welding heat sources", Metallurgical and Materials Transactions B, 15(2):299-305, 1984

[7] DuPont J.N., Marder A.R. "Thermal efficiency of arc welding processes", Welding Journal, 74(12):406-s, 1995

[8] Brown S., Song H. "Implications of three-dimensional numerical simulations of welding of large structures", Welding Research Supplement, 1992

[9] Frewin M., Scott D. "Finite element model of pulsed laser welding", Welding Journal, Welding supplement, 1999

[10] Eurocode 3 "Design of steel structures - Part 1-2: General rules -Structural fire design", 2005

[11] European Convenction for Constructional Steelwork "Manual on Stability of Steel Structures", ECCS Committee 8, Second Edition, $n^{\circ} 22,1976$. 